\title{
Mineralogia da argila e propriedades químicas de solos do Planalto Norte Catarinense
}

\author{
Clay mineralogy and chemical properties of soils in the north plateau of Santa Catarina state
}

\author{
Jaime Antônio de Almeida, Cesar Freitas Ribeiro, Marcus Vinícius Ribeiro de Oliveira* \& Leticia \\ Sequinatto
}

Universidade do Estado de Santa Catarina, Lages, SC, Brasil. *Autor para correspondência: marcusviniro@hotmail.com.

Submissão: 14/10/2016 / Aceite: 09/05/2018

\begin{abstract}
RESUMO
No Planalto Norte Catarinense são escassas as informações sobre a composição mineralógica dos solos e há poucos perfis de solo descritos e caracterizados para a região. O mapa de solos de Santa Catarina indica predominância de Cambissolos, Neossolos Litólicos e Latossolos, com Gleissolos ocupando áreas de várzeas. Esses solos ocorrem em relevo desde plano até forte ondulado, onde pequenos e médios proprietários rurais desenvolvem cultivos diversificados, com áreas expressivas de reflorestamentos com pinus. Este trabalho objetivou aprofundar o conhecimento sobre a mineralogia e as propriedades químicas de alguns desses solos, desenvolvidos de rochas sedimentares de distintas formações geológicas. Foram descritos e coletados cinco perfis de solo, sendo um Latossolo e quatro Cambissolos. Na fração terra fina seca ao ar (TFSA), foram feitas análises físicas (areia, silte, argila) e químicas de caracterização básica ( $\mathrm{pH}$ em água, carbono orgânico, $\mathrm{Ca}^{2+}, \mathrm{Mg}, \mathrm{K}, \mathrm{Na}, \mathrm{Al}, \mathrm{H}+\mathrm{Al}$ ) e com base nesses parâmetros foi calculada a CTC efetiva, CTC pH7, Soma e Saturação por Bases. Análises mineralógicas foram conduzidas na fração argila do horizonte B de cada solo, utilizando-se difratometria de raios X. Todos os solos apresentaram reação muito ácida, com baixa soma e saturação por bases e teores elevados de carbono orgânico e Al trocável. A mineralogia da fração argila revelou predomínio de caulinitas em todos os solos, com quantidades consideráveis de illita, gibbsita e vermiculita com hidroxi-Al entrecamadas.
\end{abstract}

PALAVRAS-CHAVE: Cambissolos, Latossolos, fração argila.

\begin{abstract}
In the North Plateau of Santa Catarina state, Brazil, there is little information about the mineralogical composition of the soils and a few soil profiles were described and characterized in the region. The two generalized soil maps of Santa Catarina indicate predominance of Inceptisols, Entisols and Oxisols, with hydromorphic soils occupying areas of floodplains. These soils occur in relief from plane to strong wavy, where small and medium rural farmers develop diversified crops, with significant areas with pine reforestation. This work aimed to increase the knowledge of the mineralogical and chemical properties of some of these soils developed from sedimentary rocks of different geological formations. Five soil profiles were described and sampled, included one oxisol and four Inceptisols. In fine earth, physical (sand, silt, clay) and chemical analyzes were performed ( $\mathrm{pH}$ in water, organic carbon, $\mathrm{Ca}^{2+}, \mathrm{Mg}, \mathrm{K}, \mathrm{Na}, \mathrm{Al}, \mathrm{H}+\mathrm{Al}$ ) and based on these attributes was calculated effective CEC, CEC at $\mathrm{pH} 7$, sum of bases and base saturation. Mineralogical analyzes were conducted in the clay fraction of the B horizon of each soil, using X-ray diffraction techniques. All soils showed very acid reaction, with low sum of bases and base saturation and high levels of organic carbon and exchangeable Al. The clay mineralogy revealed predominance of kaolinite in all soils, with considerable amounts of gibbsite, and vermiculite with hydroxyAl interlayered.

KEYWORDS: Inceptisols, Oxisols, clay fraction.
\end{abstract}

\section{INTRODUÇÃO}

As informações sobre os solos de Santa Catarina, disponíveis nos relatórios de levantamento de solo se restringem a resultados de análises químicas e físicas de caracterização de perfis representativos das principais classes ocorrentes (SANTA CATARINA 1973, EMBRAPA 2004). Dados sobre composição mineralógica são escassos, restringindo-se a informações para solos desenvolvidos de basalto do Oeste (BOGNOLA 1995, ALMEIDA et al. 2003), de granitos e de rochas metamórficas das serras litorâneas do 
extremo Sul (SOBRINHO 2009) e norte do Estado (BRINGHENTI 2010) e de rochas sedimentares do Planalto de Lages e Alto Vale do rio Itajaí (ALMEIDA et al. 1997).

Informações sobre a mineralogia de solos do Planalto Norte Catarinense, se resumem aos dados de um perfil de Latossolo Vermelho da região de Canoinhas, analisado para a VI Reunião de Classificação e Correlação de Solos (ROSSI et al. 2000), que indicou predomínio de caulinita, vermiculita com hidroxi-Al entrecamadas e gibbsita.

Os solos predominantes nas superfícies de relevo ondulado e forte ondulado do Planalto Norte Catarinense são os Cambissolos Húmicos Alumínicos e Alíticos, Cambissolos Háplicos Alumínicos e Alíticos e os Neossolos Litólicos Húmicos. Os Latossolos Vermelhos Húmicos também ocupam áreas expressivas nesta região, ocorrendo geralmente nas áreas de relevo suavemente ondulado nos divisores de água. Gleissolos Melânicos e Gleissolos Háplicos predominam nas áreas de relevo plano, às margens dos principais rios que cortam a região (EMBRAPA 2004). Tais solos são utilizados intensivamente com culturas anuais em agricultura diversificada, notadamente nas áreas de relevo suave ondulado e ondulado, e cultivos de arroz inundado nas áreas planas e mal drenadas. Já os solos que ocupam topografias mais acidentadas, são utilizados principalmente com reflorestamentos de pinus e eucalipto, para produção de madeira e celulose.

Devido às altas precipitações pluviométricas verificadas no Estado de Santa Catarina, o intemperismo dos seus solos geralmente foi alto, resultando em intensa lixiviação das bases, o que culminou com a formação de solos muito ácidos e com altos teores de alumínio trocável (ERNANI \& ALMEIDA 1986). Dependendo da região, do material de origem, posição no relevo e da idade dos solos, entretanto, podem ocorrer variações significativas na fertilidade química dos solos, bem como na expressão dos seus componentes mineralógicos (MONIZ 1975).

Estudos sobre a composição mineralógica das frações finas do solo constituem ferramenta essencial para explicar certas propriedades físicas e químicas dos solos, tais como a CTC da fração argila, os altos teores de Al frequentemente encontrados em muitos solos, bem como seu comportamento de consistência e capacidade de contração e expansão (AZEVEDO \& TORRADO 2009).

O presente trabalho objetivou efetuar a caracterização física, química e mineralógica de cinco perfis de solos desenvolvidos de diferentes formações geológicas sedimentares do período Permiano, ocorrentes no Planalto Norte Catarinense, procurando-se estabelecer as relações entre as propriedades físicas e químicas dos mesmos com sua composição mineralógica.

\section{MATERIAL E MÉTODOS}

Foram descritos e amostrados cinco perfis representativos das principais classes de solo do Planalto Norte Catarinense, sendo quatro perfis de Cambissolos e um perfil de Latossolo Vermelho Distrófico húmico. Os perfis foram descritos e amostrados em Major Vieira (P1), entre Três Barras e Mafra (P2), nas proximidades de Irineópolis (P3), na BR 280 próximo ao trevo da BR 116 (P4) e nas proximidades de Rio Negrinho (P5). Uma síntese dos dados e localização georreferenciada é mostrada na Tabela 1.

Tabela 1. Localização, litologia, formação geológica e relevo local, dos diferentes perfis de solo.

Table 1. Location, lithology, geological formation and local relief, the different soil profiles.

\begin{tabular}{|c|c|c|c|c|c|}
\hline Perfil & Localização & $\begin{array}{l}\text { Coordenadas } \\
\text { Geográficas }\end{array}$ & Litologia & $\begin{array}{l}\text { Formação } \\
\text { Geológica }\end{array}$ & Relevo local \\
\hline $\mathrm{P} 1$ & Município Major Vieira & $\begin{array}{l}26^{\circ} 22^{\prime} 05.88^{\prime \prime S} \\
50^{\circ} 16^{\prime} 57.53 \prime \mathrm{W}\end{array}$ & Siltitos & Rio do Rastro & so \\
\hline P2 & Município Três Barras & $\begin{array}{l}26^{\circ} 11^{\prime} 05.01 " \mathrm{~S} \\
50^{\circ} 09^{\prime} 24.45^{\prime \prime} \mathrm{W}\end{array}$ & Folhelhos & Terezina & 0 \\
\hline P3 & Município Irineópolis & $\begin{array}{l}26^{\circ} 15^{\prime} 45.44^{\prime \prime} \mathrm{S} \\
50^{\circ} 36^{\prime} 57.533^{\prime \prime} \mathrm{W}\end{array}$ & Siltitos & Rio do Rastro & so \\
\hline P4 & Município Mafra & $\begin{array}{l}26^{\circ} 10^{\prime} 46.44^{\prime \prime} \mathrm{S} \\
49^{\circ} 59^{\prime} 25.50^{\prime \prime} \mathrm{W}\end{array}$ & $\begin{array}{l}\text { Arenitos e } \\
\text { siltitos }\end{array}$ & Rio Bonito & so \\
\hline P5 & Município Rio Negrinho & $\begin{array}{l}26^{\circ} 16^{\prime} 13.13^{\prime \prime S} \\
49^{\circ} 35^{\prime} 23.05^{\prime \prime} \mathrm{W}\end{array}$ & Siltitos & Mafra & 0 \\
\hline
\end{tabular}

o = ondulado; so = suave ondulado 
As amostras foram secas ao ar, destorroadas, moídas e peneiradas em malha de $2 \mathrm{~mm}$, separandose as frações grosseiras (cascalho e calhaus, com diâmetro $>2,00 \mathrm{~mm}$ ) e a terra fina seca ao ar (TFSA). As análises laboratoriais foram divididas em físicas, químicas e mineralógicas.

Os perfis foram coletados no ano de 2013 , tendo como uso da terra, nos pontos P1 e P4 mata, no P2 e P3 capoeira e no P5 reflorestamento de pinus.

O tipo climático dominante na região é o Cfb, segundo Köeppen (FATMA et al. 2012) e a precipitação pluviométrica média anual varia de 1300 e 1400 mm (IBDF 1984).

A fração TFSA, após agitação e dispersão $\mathrm{com} \mathrm{NaOH} 1 \mathrm{M}$ foi submetida a peneiramento úmido, sendo a fração areia quantificada por pesagem. A argila foi quantificada pelo método do densímetro de Bouyoucus e o silte por diferença, todos segundo EMBRAPA (1997). O silte foi posteriormente separado da argila por sedimentação, com base na lei de Stokes. Frações da argila foram armazenadas na forma seca e em suspensão, para tratamentos posteriores destinados as análises mineralógicas.

Na TFSA, foi determinado o pH em água e em solução de $\mathrm{KCl} 1 \mathrm{M}$, na relação solo/solução de 1:1, utilizando-se potenciometria; o carbono orgânico foi determinado após oxidação úmida com dicromato de potássio em meio ácido, por titulação (TEDESCO et al. 1995). Os demais atributos químicos foram determinados segundo EMBRAPA (1997). Cálcio, magnésio e alumínio trocáveis foram extraídos com solução de $\mathrm{KCl} 1 \mathrm{M}$, sendo os dois primeiros determinados por espectrofotometria de absorção atômica e o último por titulometria de neutralização. O potássio e o sódio foram extraídos com acetato de amônio e quantificados por fotometria de chama. A acidez potencial $(\mathrm{H}+\mathrm{Al})$ foi extraída com acetato de cálcio tamponado a pH 7 e quantificada por titulometria de neutralização. A partir destes atributos foram calculadas a soma de bases (S), CTC efetiva, CTC a pH 7, saturação por bases (V) e saturação por alumínio $(\mathrm{m})$.

Os perfis de solo foram classificados até o quarto nível, com base no Sistema Brasileiro de Classificação de Solos (EMBRAPA 2013).

A fração argila foi analisada por difratometria de raios $X(D R X)$, após saturação com potássio, magnésio e magnésio com etileno glicol, sendo lidas na temperatura ambiente, em lâminas de argila orientada. As amostras com $\mathrm{K}^{+}$também foram analisadas após aquecimento em temperaturas de 100,350 , e $550 \stackrel{\circ}{\circ}$. Foi utilizado difratômetro de raios $X$ Philips automatizado, dotado de goniômetro vertical e monocromador de grafite, tubo de $\mathrm{Cu}$ e radiação $\mathrm{Ka}$. Os resultados foram interpretados com base em BROWN \& BRINDLEY (1980) e HARRIS \& WHITE (2008). A semiquantificação dos componentes minerais foi estimada com base na medida comparativa das áreas dos reflexos principais de cada mineral, com base no software HighScore Plus (DEGEN et al. 2014).

\section{RESULTADOS E DISCUSSÃO}

O Latossolo Vermelho Distrófico húmico (Unidade de Mapeamento Canoinhas, segundo SANTA CATARINA (1973) apresentou textura argilosa no horizonte $A$ e muito argilosa no $B$, com baixa relação textural $B / A$, estrutura em blocos subangulares fracamente desenvolvida e ausência de cerosidade nos subhorizontes do Bw. Abaixo deste, a estrutura é bem desenvolvida em blocos subangulares, tendo sido identificada cerosidade moderada e comum, daí sua qualificação a campo como horizonte genético Bt.

Os demais perfis, da classe dos Cambissolos, variaram de pouco profundos (P2 e P5) a profundos ( $\mathrm{P} 3$ e $\mathrm{P} 4$ ), todos com baixo gradiente textural, estrutura em blocos fracamente desenvolvida e pequena espessura do horizonte B, com ausência de cerosidade. Os perfis P2 e P3, desenvolvidos, respectivamente, de siltitos e folhelhos, apresentaram textura argilosa ou muito argilosa, enquanto os perfis P4 e P5, desenvolvidos respectivamente de siltitos e arenitos + siltitos das formações Rio Bonito e Mafra, apresentaram textura variando de média a argilosa (Tabela 2). As características de cor e granulometria variaram em função do local de coleta e da litologia do qual se desenvolveram, mas todos apresentaram predomínio de cores brunas no horizonte $\mathrm{B}$.

Todos os solos têm reação fortemente ácida, com pH em água variando de 4,1 a 4,8. Os teores de cálcio e magnésio trocáveis, assim como os valores da soma de bases (S), foram extremamente baixos, inferiores a $1 \mathrm{cmol}_{\mathrm{c}} \mathrm{kg}^{-1}$. Em praticamente todos os horizontes dos perfis, a saturação por bases $(\mathrm{V})$ foi inferior a $10 \%$, e a saturação por alumínio $(\mathrm{m})$ foi superior a $80 \%$, indicando baixíssima condição de fertilidade natural.

Os teores de Al trocável foram superiores a $4 \mathrm{cmol}_{\mathrm{c}} \mathrm{kg}^{-1}$ nos perfis P2 e P3, mas apresentam atividade da fração argila inferior a $27 \mathrm{cmol}_{\mathrm{c} \mathrm{kg}}{ }^{-1}$, caracterizando esses Cambissolos como Alumínicos. Nos perfis do Latossolo (P1) e dos Cambissolos P4 e P5, os teores de Al foram inferiores a esse limite, sendo 
distróficos (Tabela 2).

Tabela 2. Atributos químicos e granulometria de cinco perfis de solos do Planalto Norte Catarinense.

Table 2. Chemical attributes and particle size of five profiles of the North Plateau of Santa Catarina soils.

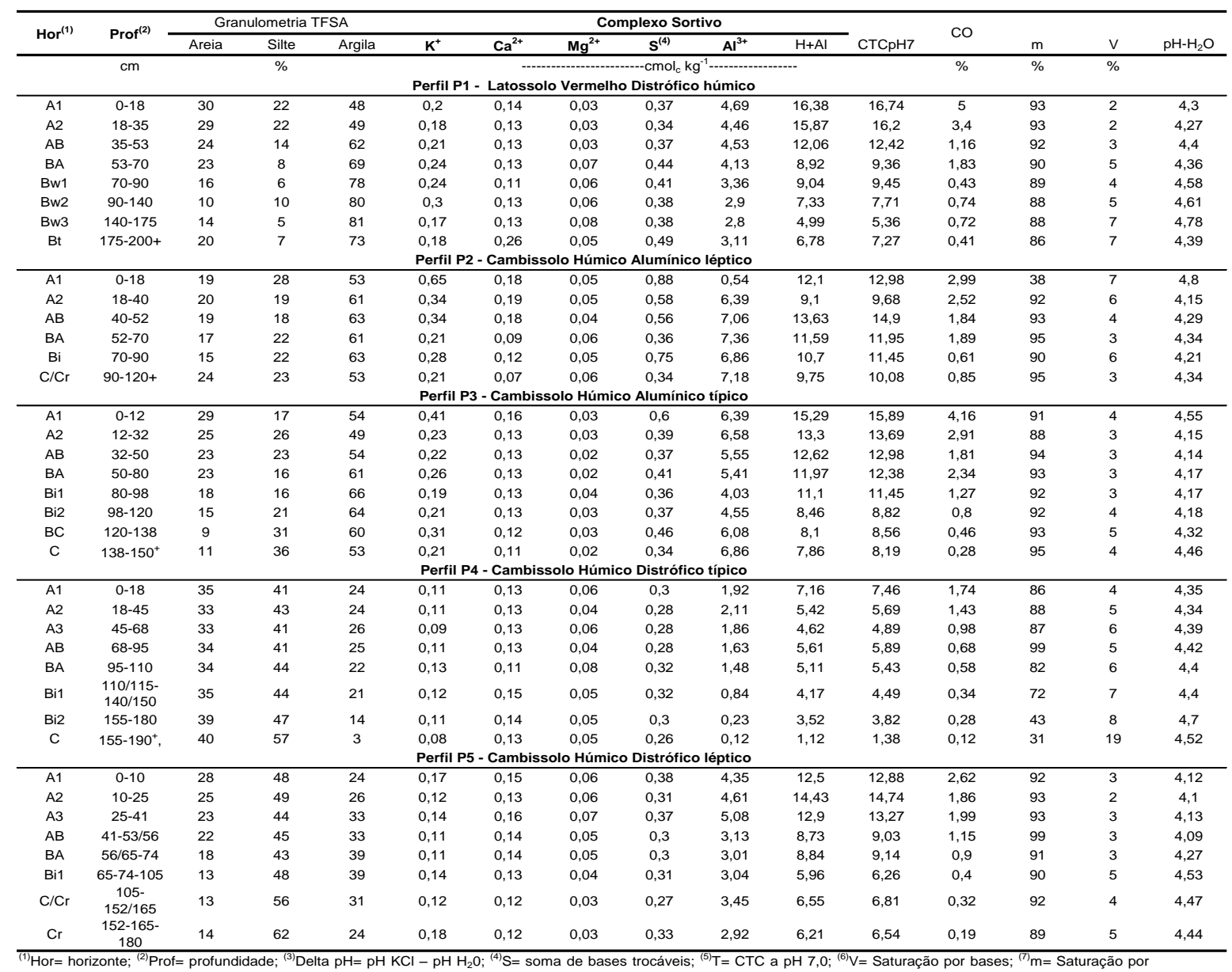

alumínio; ${ }^{(8)} \mathrm{M}=\mathrm{P}$ pelo método de Mehlich; ${ }^{\left({ }^{9} \mathrm{O}\right.} \mathrm{O}=\mathrm{P}$ pelo método de Olsen

Os teores de carbono orgânico foram geralmente altos, consequência do clima mais frio dominante na região, que favoreceram grande acumulação de matéria orgânica. Nos solos mais argilosos, os teores geralmente são mais altos devido a maior estabilidade do húmus ao interagir com a argila (STEVENSON 1982).

As análises mineralógicas da fração argila, efetuadas em três subhorizontes de cada perfil, $(A, B$ e $\mathrm{C}$, ou $\mathrm{Cr}$ ), indicaram, para todos os solos e horizontes, o predomínio de caulinita, identificada pelos reflexos mais intensos em torno de 0,72 e 0,36 e 0,24 nm (Figuras 1 a 5). Entretanto, na maioria dos solos, esses reflexos são largos, com assimetria para ângulos $2 \theta$ mais baixos na posição $0,72 \mathrm{~nm}$ e para ângulos mais altos na posição $0,36 \mathrm{~nm}$, feição que frequentemente é atribuída a interestratificação de camadas 2:1 nos cristais de caulinitas (AZEVEDO \& TORRADO 2009, KÄMPF et al. 2012). No entanto, a natureza desses argilominerais, assim como a estimativa do grau dessa interestratificação não pode ser realizada. Em proporções menores, porém altas em alguns solos, ocorrem minerais de camada 2:1 expansíveis (VHE), com reflexos em torno de 1,4 nm, micas ou illitas $(\sim 1,0,0,5$ e $0,33 \mathrm{~nm})$, gibbsita $(\sim 0,48$ e 0,44 nm) e óxidos de ferro $(\sim 0,27$ e $0,25 \mathrm{~nm})$.

No Latossolo Vermelho Distrófico de Major Vieira (P1), derivado de siltitos da formação Rio do Rasto, os reflexos mais intensos ocorreram em posições compatíveis com as dos planos 001 e 002 da caulinita, mas como são largos e assimétricos, podem indicar participação de minerais interestratificados 1:1-2:1 (SRÓDON 2006, AZEVEDO \& TORRADO 2009) em associação com caulinitas puras. Ocorrem também quantidades expressivas de vermiculitas com polímeros de hidroxi-Al entrecamadas (VHE), indicadas pelo pico relativamente intenso em 1,435 nm, e de gibbsita (picos em 0,483 e 0,436 nm). Na amostra do horizonte $\mathrm{Bt}$, além desses minerais, ocorre também baixa quantidade de mica ou illita, indicada pelo pequeno reflexo em torno de 1,0 nm. (Figura 1). Os picos em 0,269 e 0,250 nm são da hematita, principal óxido de ferro presente e responsável pela cor vermelha em todos os horizontes do solo. A 
hipótese de VHE foi admitida como mais provável, tendo em vista a presença de expressivas quantidades de mica no material originário, ausência de expansão das camadas no tratamento com magnésio e etileno glicol e pela contração incompleta das camadas nos tratamentos de aquecimento das amostras saturadas com potássio (dados não mostrados). Nas amostras saturadas com $\mathrm{K}$ e aquecidas a $550{ }^{\circ} \mathrm{C}$ o reflexo principal dos minerais de camada 2:1 ocorreu na posição de $1,18 \mathrm{~nm}$, indicando vermiculitas com alta intercalação de polímeros de hidroxi-Al entrecamadas (BARNISHEL \& BERTSCH 1989).

As quantidades de VHE e gibbsita tiveram ligeiro aumento da base para o topo do perfil (Tabela 3), decorrente da maior intensidade do intemperismo nos horizontes superiores, a qual pode ter favorecido a destruição de parte das caulinitas com consequente aumento relativo na proporção daqueles minerais.

A atividade da fração argila para o horizonte Bw2, sem correção do carbono e calculada com base CTC a pH 7, foi de $9,64 \mathrm{cmolc}_{\mathrm{cg}}{ }^{-1}$ de argila, valor relativamente baixo quando se considera as expressivas quantidades de VHE (21\% a $23 \%$, conforme Tabela 3$)$ e eventuais interestratificados no solo. Há que ser considerado, no entanto, que se trata de vermiculitas que tem sua carga original fortemente reduzida pela presença das altas quantidades de polímeros de hidroxi-Al (BARNISHEL \& BERTSCH 1989). A presença de gibbsita, cuja CTC é praticamente nula, também reforça esta interpretação, já que apresenta saldo de carga líquida positiva em valores de pH baixo. Embora a associação das fases minerais caulinita $+\mathrm{VHE}+$ gibbsita possa parecer incompatível, esta composição tem sido identificada em muitos locais em solos com elevado grau de intemperização (BHATTACHARYYA et al. 2000). KARATHANASIS \& HAJEK (1983) demonstraram, através de estudos termodinâmicos, que vermiculitas com alta intercalação com polímeros de Al nas entrecamadas podem apresentar estabilidade maior do que a caulinita, indicando que com o avanço do intemperismo, tais minerais podem ser preservados no solo, em conjunto com caulinita e gibbsita.

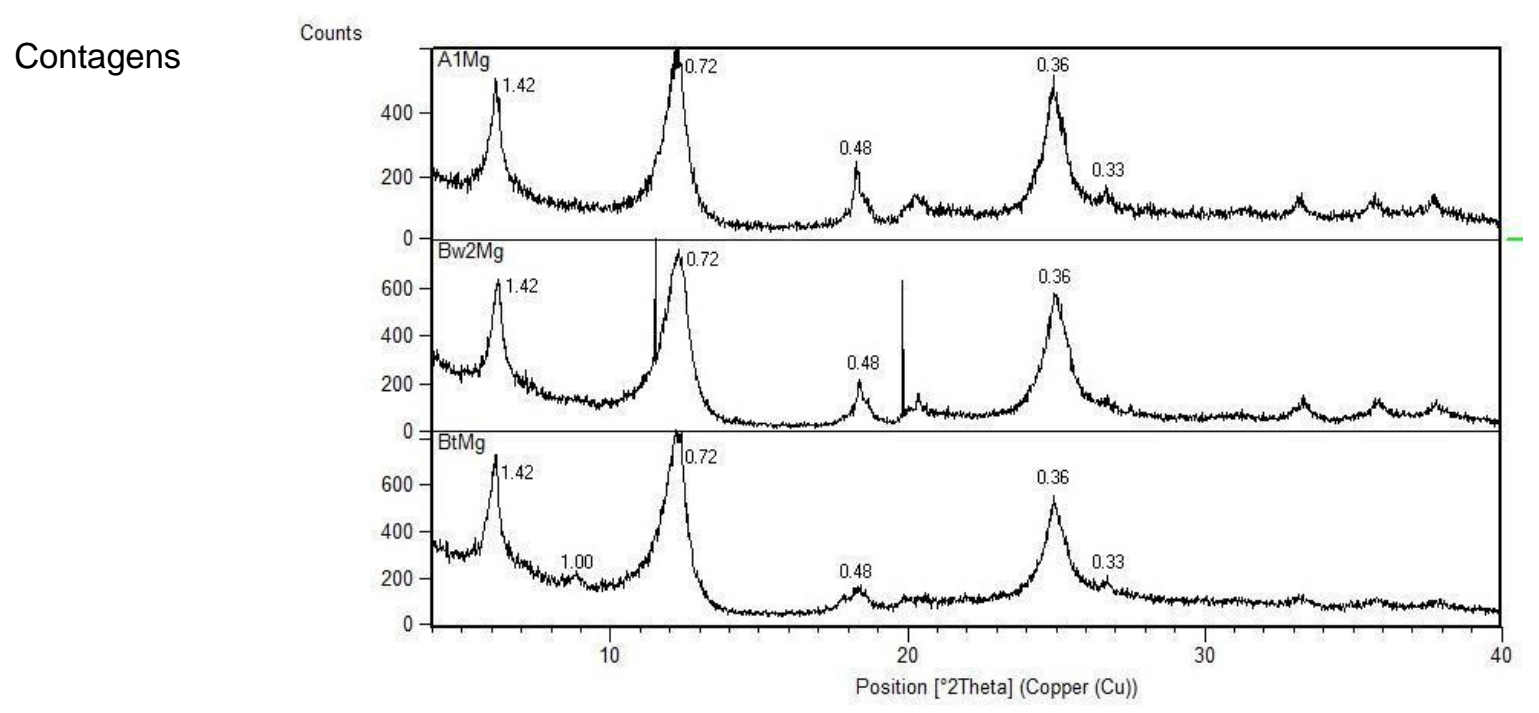

Posição [ ${ }^{\circ} 2$ Teta] (Cobre $(\mathrm{Cu})$

Figura 1. Difratogramas da fração argila orientada de amostras saturadas com magnésio e lidas à temperatura ambiente, dos principais horizontes do perfil de Latossolo Vermelho Distrófico húmico (P1, Major Vieira). Espaçamentos em nanômetros ( $\mathrm{nm})$.

Figure 1. XRD patterns of the clay fraction of oriented samples saturated with magnesium and read at room temperature, the main horizons of Rhodic profile Dystrophic humic (P1, Major Vieira). Gaps in nanometers $(\mathrm{nm})$.

No perfil de Cambissolo Húmico Alumínico léptico de Mafra (P2), derivado da alteração de folhelhos da formação Terezina, a composição mineral da fração argila é similar, porém as quantidades variam entre os horizontes. No horizonte $\mathrm{Cr}$, a quantidade de micas e, ou illitas (reflexos em 1,0, 0,5 e 0, $33 \mathrm{~nm}$ ) é maior do que a de caulinitas (reflexos em $0,72,0,36$ e $0,24 \mathrm{~nm}$ ). Parte das micas pode ter sido transformada em vermiculitas, evidenciadas pelo pequeno reflexo em torno de 1,4 nm (Figura 2). Observa-se que da base para o topo do perfil, há um incremento da área dos reflexos principais da caulinita $(0,72 \mathrm{~nm})$ e dos minerais de camada 2:1 (1,4 nm), indicando que com o aumento da taxa de intemperismo, parte das micas pode ter 
sido destruída, com neoformação de caulinita, e parte pode ter sofrido transformação no estado sólido para formação de vermiculitas. Nos horizontes $A B$ e Bi, por exemplo, a área dos reflexos da caulinita supera ou é similar ao das micas e, ou illitas (Tabela 3 ). Os tratamentos com etileno glicol não mostraram modificação na posição dos reflexos de $1,4 \mathrm{~nm}$; já os tratamentos térmicos evidenciaram deslocamento dos reflexos de $1,4 \mathrm{~nm}$ para posições variáveis entre 1,25 a $1,08 \mathrm{~nm}$, indicando um colapso incompleto das camadas 2:1 pela alta intercalação de polímeros de hidroxi-Al entrecamadas, confirmando tratar-se de VHE. Os reflexos da caulinita neste solo são relativamente largos (LMA em torno de $0,42{ }^{\circ} 2 \theta$ ) (Tabela 3 ), porém mais simétricos (Figura 2), indicando provavelmente caulinitas mais bem cristalizadas.

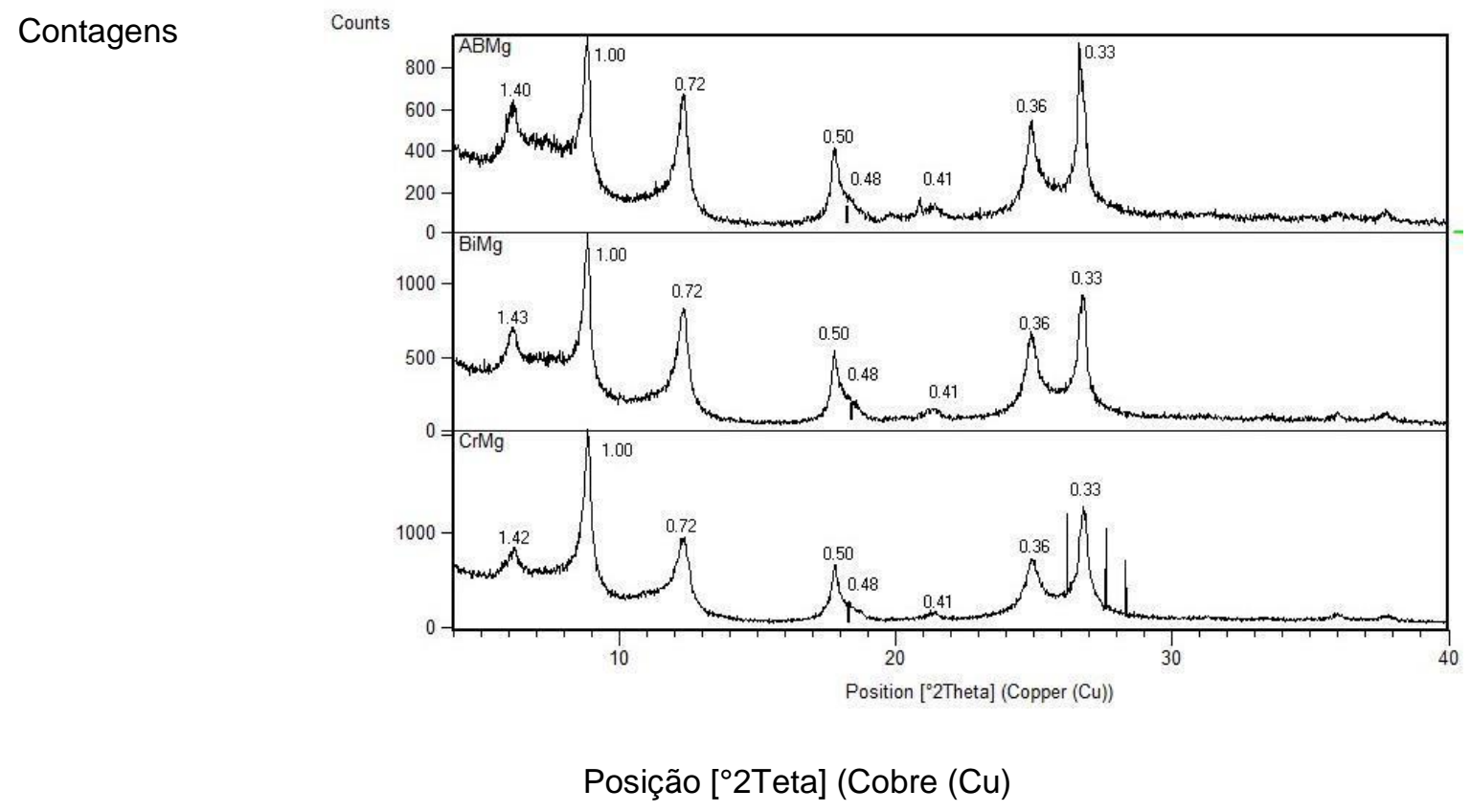

Figura 2. Difratogramas da fração argila orientada de amostras saturadas com magnésio e lidas à temperatura ambiente, dos principais horizontes do perfil de Cambissolo Húmico Alumínico léptico (P2, Mafra). Espaçamentos em nanômetros (nm).

Figure 2. XRD patterns of oriented clay fraction samples saturated with magnesium and read the ambient temperature of the main horizons Haplumbrept soil profile (P2, Mafra). Gaps in nanometers ( $\mathrm{nm})$.

A quantidade de illitas foi de $58 \%$ e a de VHE de $9 \%$ no horizonte Cr. Da base para o topo do perfil, as quantidades de illita caem para $39 \%$, enquanto aumenta proporcionalmente a quantidade de VHE para $18 \%$ (Tabela 3).

A atividade da fração argila para o horizonte $\mathrm{Bi}$, calculada sem correção do carbono, foi de 18,17 $\mathrm{cmol}_{\mathrm{c}} \mathrm{kg}^{-1}$ de argila, bem superior, portanto, aos valores geralmente atribuídos a caulinita. Grande parte desse aumento se deve, provavelmente, a contribuição das altas quantidades de illitas, e da presença da VHE.

No perfil de Cambissolo Húmico Alumínico típico de Irineópolis (P3), derivado de siltitos da formação Rio do Rasto, os componentes minerais da fração argila são similares, mas apresentam variações quantitativas entre os horizontes. As áreas dos reflexos na posição do plano 001 da caulinita predominam sobre as dos reflexos dos demais minerais, porém são muito largos (LMA em torno de $0,85{ }^{\circ} 2 \theta$ ) e fortemente assimétricos, formando uma "saia" em direção aos ângulos $2 \theta$ mais baixos. Esta feição é geralmente indicativa da contribuição de interestratificados 1:1-2:1 em associação com caulinitas (SRÓDON 2006, AZEVEDO \& TORRADO 2009), minerais dominantes em todos os horizontes do solo. No horizonte C, como segundo componente importante ocorrem reflexos de micas e, ou illitas, em torno de $1,0 \mathrm{~nm}$, seguido de reflexos minerais de camada $2: 1(1,4 \mathrm{~nm})$ e de gibbsita $(0,48$ e $0,43 \mathrm{~nm})$, ambos em pequenas quantidades em relação aos demais (Figura 3). Nos horizontes Bi e A1, a intensidade e a área dos reflexos da mica e, ou illita se reduzem, com aumento concomitante na área dos reflexos dos minerais de camada 2:1 (1,4 nm) e da gibbsita. Este comportamento indica que, com o aumento do grau de intemperismo nos horizontes mais superficiais, as micas originalmente presentes podem ter sido transformadas em vermiculitas, provavelmente com intercalação de polímeros de hidroxi-Al nas entrecamadas, assim como aumentaram as quantidades de gibbsita. Do mesmo modo que no perfil anterior, a impregnação com etileno 
glicol não evidenciou mudança na posição do reflexo de $1,4 \mathrm{~nm}$ e os tratamentos térmicos indicaram colapso incompleto das camadas 2:1, confirmando tratar-se de VHE (BARNISHEL \& BERTSCH 1989).

A quantidade de micas e, ou illitas é alta no horizonte C (34\%), enquanto as de VHE e de gibbsita são baixas neste horizonte ( 3 e $5 \%$, respectivamente). Da base para o topo, aumentam as quantidades de VHE e gibbsita, enquanto as quantidades de micas e, ou illitas se reduzem para $6 \%$ (Tabela 3 ).

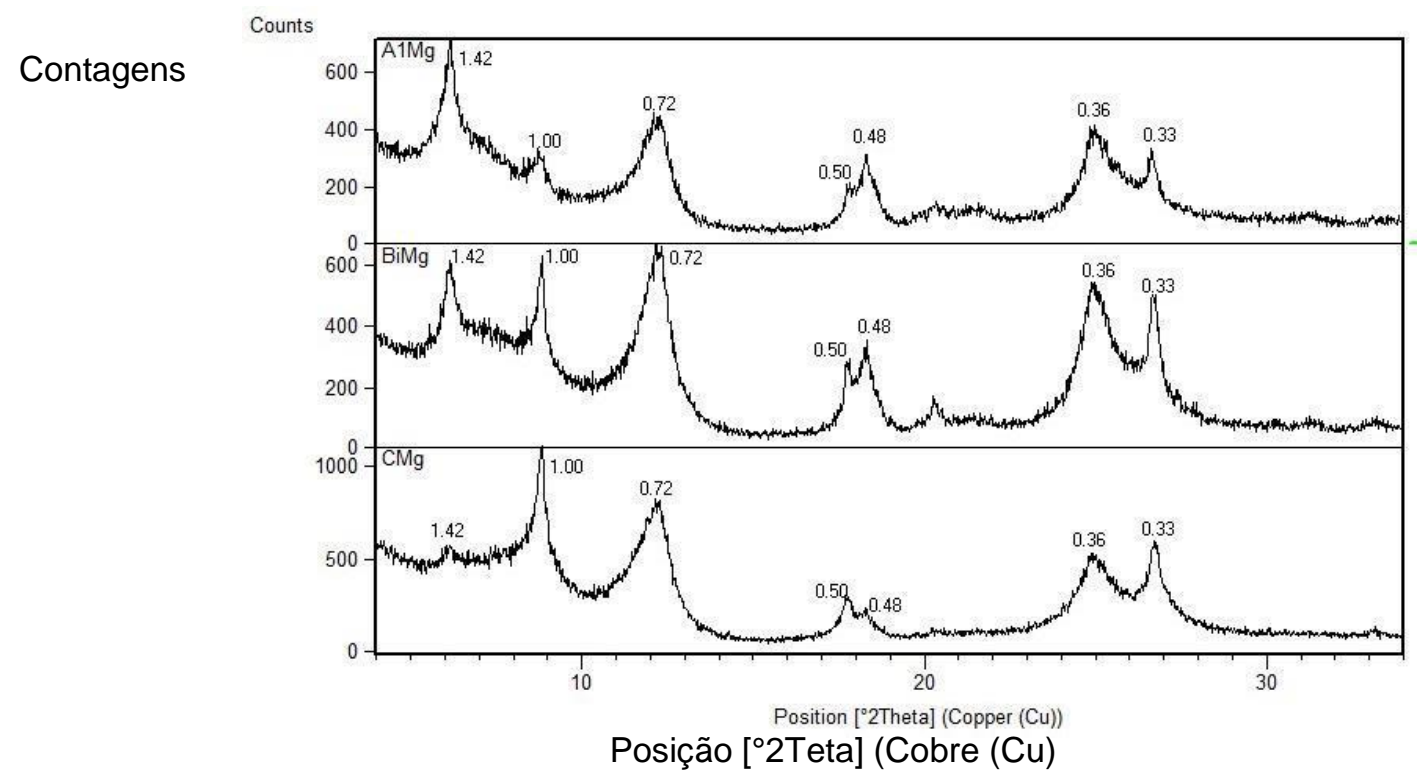

Figura 3. Difratogramas da fração argila orientada de amostras saturadas com magnésio e lidas à temperatura ambiente, dos principais horizontes do perfil de Cambissolo Húmico Alumínico típico (P3, Irineópolis). Espaçamentos em nanômetros (nm).

Figure 3. XRD patterns of oriented clay fraction samples saturated with magnesium and read the ambient temperature of the main horizons Cambisol profile Humic typical alumínico (P3, Irineópolis). Gaps in nanometers $(\mathrm{nm})$.

A atividade da fração argila para o horizonte $\mathrm{Bi}$, calculada sem correção do carbono, foi de 13,78

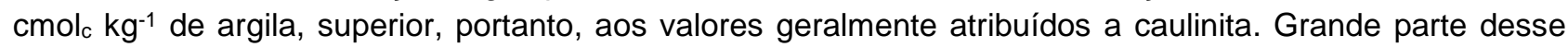
aumento se deve, provavelmente, a contribuição das altas quantidades de illitas, e da presença da VHE.

No perfil de Cambissolo Húmico Distrófico típico coletado entre Canoinhas e Mafra (P4), derivado de arenitos da formação Rio Bonito e com textura média no horizonte $\mathrm{B}$, a composição mineralógica foi a mais simples dentre os solos analisados, com muita similaridade entre os horizontes. Reflexos intensos e relativamente simétricos em $0,72\left(\right.$ LMA em torno de $\left.0,44{ }^{\circ} 2 \theta\right)$ e $0,36 \mathrm{~nm}$ indicam a caulinita como mineral absolutamente dominante em todos os horizontes do solo. No horizonte $C$, pequeno reflexo em torno de 1,0 $\mathrm{nm}$ indica provavelmente illita. Nos demais horizontes, além de baixas quantidades de illita, observam-se reflexos um pouco mais intensos de filossilicatos de camada 2:1, em torno de 1,4 nm (Figura 4). Os tratamentos térmicos e de glicolação confirmaram a presença de VHE, em baixas quantidades nos horizontes mais superficiais (dados não mostrados).

Neste perfil, as quantidades de caulinita são muito altas, e com pequena evidência de reflexos de mica no horizonte $\mathrm{C}$, mas observa-se ligeiro incremento de VHE da base para o topo, chegando a $12 \%$ no horizonte $\mathrm{A} 1$ (Tabela 3 ), provavelmente formadas às espessas da alteração das micas.

A atividade da fração argila para o horizonte Bi2, calculada sem correção do carbono, foi de 21,38 $\mathrm{cmol}_{\mathrm{c}} \mathrm{kg}^{-1}$ de argila, valor bem acima do esperado para este solo considerando a textura mais arenosa, o predomínio de caulinitas e as baixas quantidades de VHE. Há que considerar, neste caso, que o método de cálculo pode ter superestimado a atividade da fração argila, conforme já tem sido verificado em outras situações de solos de textura mais arenosa (ROSSI et al. 2000). Conforme EMBRAPA (2013), o método de estimativa da atividade da fração argila para solos de textura muito arenosa não é recomendado, por geralmente superestimar essa atividade.

No perfil de Cambissolo Húmico Alumínico típico de Rio Negrinho (P5), derivado da siltitos da formação Mafra, a composição mineral da fração argila foi similar à do solo anterior (P4), porém os reflexos de 0,72 e $0,36 \mathrm{~nm}$ são muito largos e assimétricos (LMA em torno de $0,80{ }^{\circ} 2 \theta$ no reflexo de $0,72 \mathrm{~nm}$ ), indicando provavelmente caulinitas em associação com interestratificados 1:1-2:1. Esses minerais são 
dominantes em todos os horizontes. No horizonte $\mathrm{Cr}$, ocorrem micas e, ou illitas (reflexos em torno de 1,0 $\mathrm{nm}$ ) como segundo componente importante. Nos horizontes acima do saprólito ( $\mathrm{Cr}$ ), diminuem as quantidades de mica e aumentam as quantidades de filossilicatos de camada 2:1, com reflexos em torno de $1,4 \mathrm{~nm}$, os quais com base nos resultados dos tratamentos térmicos e de glicolação, indicaram tratar-se de VHE.

Neste solo, a proporção de caulinita no $\mathrm{Cr}$ é muito alta (83\%), com redução para $68 \%$ no $\mathrm{A} 1$. A proporção relativa de micas e, ou ilitas é de $14 \%$ nesse mesmo horizonte, com redução da base para o topo do perfil, na mesma proporção em que aumentam as VHE (Tabela 3).

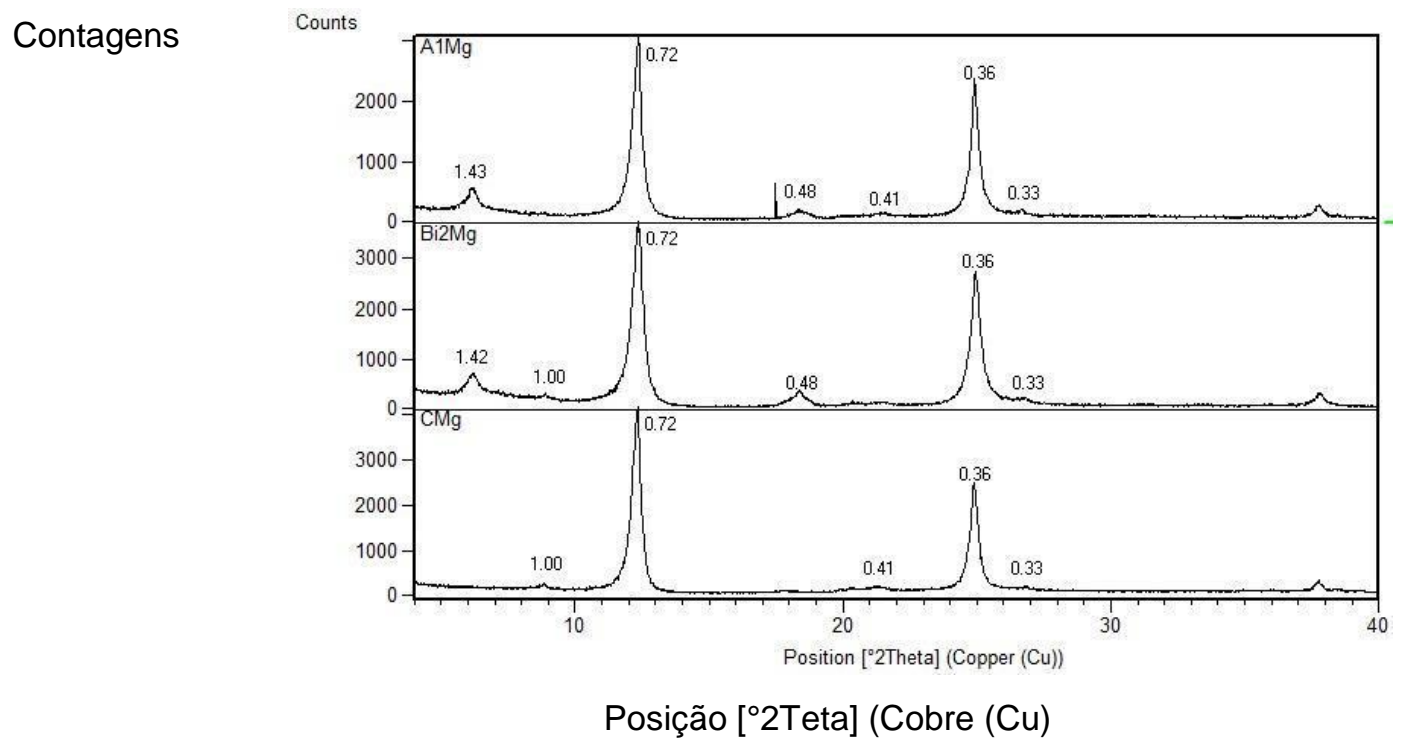

Figura 4. Difratogramas da fração argila orientada de amostras saturadas com magnésio e lidas à temperatura ambiente, dos principais horizontes do perfil de Cambissolo Húmico Distrófico típico (P4, Canoinhas). Espaçamentos em nanômetros (nm).

Figure 4. XRD patterns of oriented clay fraction samples saturated with magnesium and read the ambient temperature of the main horizons Cambisol profile Humic Haplorthox (P4, Canoinhas). Gaps in nanometers $(\mathrm{nm})$.

Tabela 3. Estimativa da proporção relativa dos filossilicatos e de gibbsita na fração argila, com base na área relativa dos reflexos de cada mineral, e largura a meia altura do reflexo na posição do plano 001 das "caulinitas".

Table 3. Estimate the relative proportion of phyllosilicates and gibbsite in the clay fraction, based on the relative area of the reflections of each mineral, and width reflection of half height in the plane position 001 "kaolinite".

\begin{tabular}{lllllll}
\hline Perfil & Horizonte & A 2:1HE & A Mi/ll & A Ct & A Gb & LMA Ct \\
\hline \multirow{2}{*}{ P1 } & A1 & 25 & 0 & 64 & 11 & 0,7786 \\
& Bw2 & 21 & 0 & 71 & 08 & 0,9449 \\
& $\mathrm{Bt}$ & 23 & $\mathrm{ne}^{*}$ & 71 & 06 & 0,9662 \\
\hline & $\mathrm{AB}$ & 18 & 39 & 43 & $\mathrm{ne}$ & 0,4275 \\
P2 & $\mathrm{Bi}$ & 14 & 44 & 42 & ne & 0,4410 \\
& $\mathrm{Cr}$ & 09 & 58 & 33 & ne & 0,4119 \\
\hline & $\mathrm{A} 1$ & 32 & 6 & 41 & 21 & 0,7740 \\
P3 & $\mathrm{Bi} 2$ & 14 & 15 & 54 & 17 & 0,8337 \\
& $\mathrm{C}$ & 03 & 34 & 58 & 05 & 0,8647 \\
\hline & $\mathrm{A} 1$ & 12 & 0 & 84 & 04 & 0,4211 \\
P4 & $\mathrm{Bi} 2$ & 09 & 02 & 83 & 06 & 0,4841 \\
& $\mathrm{C}$ & 01 & 0 & 99 & - & 0,4092 \\
\hline & $\mathrm{A} 1$ & 25 & 0 & 68 & 07 & 0,6767 \\
P5 & $\mathrm{Bi}$ & 06 & 03 & 86 & 05 & 0,6440 \\
& $\mathrm{Cr}$ & 02 & 14 & 83 & 01 & 0,7695 \\
\hline
\end{tabular}

*ne = mineral presente, com área não estimável pela técnica utilizada. 
A atividade da fração argila para o horizonte $\mathrm{Bi}$, calculada sem correção do carbono, foi de 16,05 $\mathrm{cmol}_{\mathrm{c}} \mathrm{kg}^{-1}$ de argila, valor que supera o da caulinita, e confirma a contribuição das VHE e possivelmente dos interestratificados 1:1-2:1 no aumento da CTC desses solos.

A composição mineralógica constatada na maioria dos solos é diferenciada, portanto, da maioria dos solos mais intemperizados que ocorrem na região tropical do Brasil, onde geralmente predomina a caulinita em associação com óxidos de alumínio como a gibbsita e óxidos de ferro. Dos cinco solos estudados, apenas dois, correspondendo aos perfis P2 (derivado de folhelhos) e P4 (derivado de arenitos), apresentaram reflexos nas posições 0,72 e 0,36 nm mais claramente identificadores de caulinitas puras, pois apresentaram menor largura a meia altura (LMA) e pouca ou nenhuma assimetria dos reflexos (Tabela 3 e Figuras 2 e 4). Nos demais solos, os reflexos nestas posições são muito largos e assimétricos, com LMA muito superior à referida para a maioria das caulinitas encontradas em distintos ambientes brasileiros (MELO et al. 2001, MELO et al. 2002). Este comportamento, como já mencionado, indica provável participação de interestratificados 1:1-2:1 em associação com caulinitas, cuja presença foi detectada nas amostras dos perfis P1, P3 e P5, incluindo, portanto, sua presença também no Latossolo Vermelho (P1).

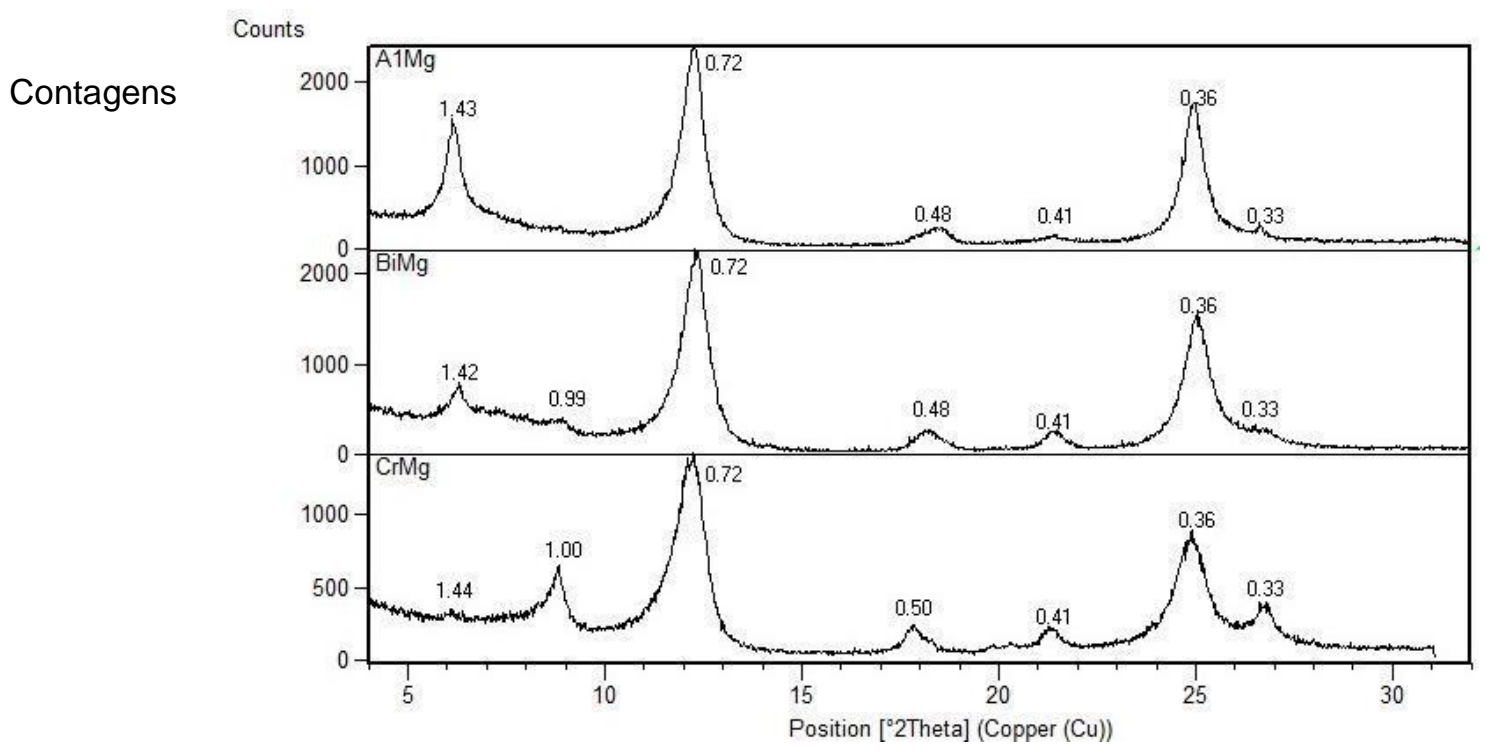

Posição [ ${ }^{\circ 2 T e t a]}$ (Cobre $\left.(\mathrm{Cu})\right)$

Figura 5. Difratogramas da fração argila orientada de amostras saturadas com magnésio e lidas à temperatura ambiente, dos principais horizontes do perfil de Cambissolo Húmico Alumínico típico (P5, Rio Negrinho), Espaçamentos em nanômetros (nm).

Figure 5. XRD patterns of oriented clay fraction samples saturated with magnesium and read the ambient temperature of the main horizons Cambisol profile Humic typical alumínico (P5, Rio Negrinho) Gaps in nanometers $(\mathrm{nm})$.

A persistência de expressivas quantidades de filossilicatos de camada 2:1, do tipo VHE, assim como de interestratificados de camada 1:1-2:1, em associação com caulinitas, geralmente dominantes nesses solos, são indicativos de variações nas condições ambientais durante a história evolutiva dos mesmos, conforme já demonstrado em outras situações por BHATTACHARYYA et al. (2000) na Índia e por BORTOLUZZI et al. (2008) em solos do Rio Grande do Sul. Filossilicatos expansíveis, tais como vermiculitas e esmectitas, geralmente formam-se em ambientes com baixo fluxo lixiviante, portanto mais secos (KÄMPF et al. 2012). Mudanças (bruscas) do clima para uma condição mais úmida podem destruir grande parte destes minerais, com formação de novos minerais, tais como caulinita ou mesmo gibbsita. Porém, quando a maior parte das bases é rapidamente removida e o ambiente se torna mais ácido, parcela desses minerais pode sofrer intercalação com polímeros de Al nas entrecamadas, tornando-se termodinamicamente estáveis e desse modo podem persistir no solo em associação com caulinitas, conforme já destacado por KARATHANASIS \& HAJEK (1983). Assim, VHE e EHE, como também minerais em estágios intermediários de transformação dos filossilicatos de camada 2:1 para caulinitas, tais como os interestratificados, podem persistir mesmo nos ambientes em que solos sofreram alto grau de intemperização. 
Nos solos estudados, embora esses minerais tenham sido detectados em quantidades expressivas, sua presença teve pequena influência no aumento da CTC, provavelmente por tratar-se de minerais com alta intercalação com polímeros de hidroxi-Al nas entrecamadas, que reduzem drasticamente a CTC em relação às formas puras desses minerais. Ademais, o aumento da CTC não se traduziu em melhoria das propriedades químicas dos solos, uma vez que, na totalidade dos casos, os valores da soma de bases foram inferiores a $0,9 \mathrm{cmol}_{\mathrm{c}} \mathrm{kg}^{-1}$, e a saturação por alumínio (m\%) foi superior a $80 \%$ na maior parte dos casos. Portanto, apesar do saldo elevado de cargas negativas, estas infelizmente estão saturadas por cátions ácidos aumentando o poder tampão de acidez do solo. Tais propriedades denotam tratar-se de solos formados em ambiente fortemente lixiviante, compatíveis com as características climáticas atuais da região, que apresenta altos excedentes hídricos em função dos altos volumes de precipitação e baixa evapotranspiração, condicionada pelo clima mais frio.

Infere-se desses resultados, que as opções de uso e manejo das terras onde esses solos ocorrem requerem atenção especial. As principais restrições ao uso agrícola se referem a baixa soma de bases e elevadas quantidades de alumínio, não só nas suas formas trocáveis, como também não trocáveis, representadas por fontes potenciais de acidez relacionadas ao Al complexado pela matéria orgânica e aos polímeros inorgânicos. Tais compostos condicionam alto tamponamento do $\mathrm{pH}$, exigindo doses muito altas de calcário para correção da acidez e eliminação das fontes de Al tóxico. Ademais, a presença de expressivas quantidades de minerais de camada 2:1 com forte intercalação com polímeros de alumínio pode aumentar a fixação de fosfatos e de potássio nas entrecamadas, devendo estas características ser levadas em conta nas estratégias de adubação diferenciada com esses nutrientes para as culturas.

\section{CONCLUSÃO}

Independentemente da classe taxonômica, todos os solos do Planalto Norte Catarinense avaliados apresentaram reação fortemente ácida, baixos valores de soma e saturação por bases e teores elevados de carbono orgânico e Al extraível com KCl $1 \mathrm{~mol} \mathrm{~L}^{-1}$, compatíveis com as condições de clima úmido e frio que predominam na região que favoreceram intensa lixiviação dos solos.

A composição da fração argila foi relativamente similar entre os solos, geralmente com predomínio dos reflexos na posição da caulinita, secundada vermiculitas com polímeros de hidroxi-Al entrecamadas (VHE), illita e gibbsita.

Para uma mesma classe de solo, as análises mineralógicas indicaram que as proporções relativas de VHE foram sempre maiores nos horizontes superficiais, oriundas principalmente da transformação das micas presentes no material originário; as proporções relativas de gibbsita seguiram a mesma tendência, apesar de ocorrerem em quantidades mais baixas.

Apesar das proporções relativamente altas de filossilicatos de camadas 2:1 na maioria dos solos, estas não se traduziram em incrementos expressivos na CTC e na atividade da fração argila dos solos, em função de que apresentam alta intercalação com polímeros de hidróxi-Al entre camadas.

A composição mineralógica da fração argila, associada à textura argilosa e aos altos conteúdos de carbono da maioria dos solos, são compatíveis com o maior tamponamento da acidez desses solos em relação aos que ocorrem no ambiente mais tropical brasileiro.

\section{REFERÊNCIAS}

ALMEIDA JA et al. 1997. Caracterização mineralógica de Cambissolos originados de rochas pelíticas nos Patamares do Rio Itajaí e no Planalto de Lages, Santa Catarina. Revista Brasileira de Ciência do Solo 21: 181-190.

ALMEIDA JA et al. 2003. Cor de solo, formas do fósforo e adsorção de fosfatos em Latossolos desenvolvidos de basalto do extremo-sul do Brasil. Revista Brasileira de Ciência do Solo 27: 985-1002.

AZEVEDO AC \& TORRADO PV. 2009. Esmectita, Vermiculita, Minerais com Hidroxi-Entrecamadas e Clorita. In: MELO VF \& ALLEONI LRF. (Eds). Química e mineralogia do solo. p. 381-426.

BARNHISEL RI \& BERTSCH PM. 1989. Chlorites and hydroxy-interlayered vermiculite and smectite. In: DIXON JB \& WEED SB. (Eds). Minerals in soil environments. Madison: Soil Science Society of America. p.729-788.

BOGNOLA IA. 1995. Caracterização química, física e mineralógica de solos intermediários entre Latossolos Brunos e Latossolos Roxos. Dissertação (Mestrado). Viçosa: UFV. 205p.

BORTOLUZZI EC et al. 2008. Mineralogia de partículas envolvidas na formação de gradiente textural em um argissolo subtropical. Revista Brasileira de Ciência do Solo 32: 997-1007.

BHATTACHARYYA T et al. 2000. Formation of gibbsite in the presence of 2:1 minerals: an example from Ultisols of northeast Índia. Clay Minerals 35: 827-840.

BRINGHENTI I. 2010. Mineralogia e gênese dos solos das serras litorâneas do norte catarinense. Dissertação (Mestrado em Ciência do Solo). Lages: UDESC. 110p.

BROWN G \& BRINDLEY G W. 1980. X-ray diffraction procedures for clay mineral identification. In: BRINDLEY GW \& 
BROWN G. (Eds.) Crystal structures of clay minerals and their X-ray identification. London: Mineralogical Society. p.305-360.

DEGEN T et al. 2014. The HighScore suite. Powder Diffraction. 29: 13-18.

EMBRAPA. 2004. Empresa Brasileira de Pesquisa Agropecuária. Solos do Estado de Santa Catarina. Rio de Janeiro: Embrapa Solos. 745p.

EMBRAPA. 1997. Empresa Brasileira de Pesquisa Agropecuária. Manual de métodos de análise de solo. Rio de Janeiro: Embrapa Solos. 212p.

EMBRAPA. 2013. Empresa Brasileira de Pesquisa Agropecuária. Sistema Brasileiro de Classificação de Solos. 3.ed. Brasília: Embrapa. 353p.

ERNANI PR \& ALMEIDA JA. 1986. Comparação de métodos analíticos para avaliar a necessidade de calcário dos solos do estado de Santa Catarina. Revista Brasileira de Ciência do Solo 10: 143-150.

FATMA 2012. Fundação de Amparo à Tecnologia e ao Meio Ambiente. Programa uso racional de água e solo no Planalto Norte Catarinense: "Planorte água e solo". Comitê Rio Canoinhas. 31p.

HARRIS W \& WHITE GN. 2008. X-ray diffraction techniques for soil mineral identification. In: ULERY AL \& DREES R. (Eds.) Methods of soil analysis. Part 5. Mineralogical methods. Madison: Soil Science Society of America. p. 81-116.

IBDF. 1984. Instituto Brasileiro de Desenvolvimento Florestal. Inventário florestal nacional: florestas plantadas: Paraná e Santa Catarina. Brasília: IBDF. 284p.

KÄMPF N et al. 2012. Mineralogia de solos brasileiros. In: KER et al. (Eds.). Pedologia: fundamentos. Viçosa: SBCS. p. 81-145.

KARATHANASIS AD \& HAJEK BF. 1983. Transformation of smectite to kaolinite in naturally acid soil systems: Structural and thermodynamic consideration. Soil Science Society of America Journal 47: 158-163.

MELO VF et al. 2001. Chemical and Mineralogical Properties of Kaolinite-Rich Brazilian Soils. Soil Science Society of America Journal 65: 1324-1333.

MELO VF et al. 2002. Propriedades químicas e cristalográficas da caulinita e dos óxidos de ferro em sedimentos do Grupo Barreiras no Município de Aracruz, Estado do Espírito Santo. Revista Brasileira de Ciência do Solo 26: 53-64.

MONIZ AC. 1975. Decomposição de rochas e formação de minerais de argila. In: MONIZ AC (Ed.). Elementos de Pedologia. São Paulo: Edusp. p. 305-323.

SOBRINHO JBP et al. 2009. Mineralogia, propriedades químicas e classificação de solos das Serras do Leste Catarinense. Revista de Ciências Agroveterinárias 8: 9-24.

ROSSI M. et al. 2000. Descrição de perfis. In: EMBRAPA (org). VI Reunião de Correlação, Classificação e Aplicação de Levantamentos de Solo Rio Grande do Sul / Santa Catarina / Paraná. Porto Alegre. p 16-123.

SANTA CATARINA. 1973. Secretaria da Agricultura. Levantamento de reconhecimento dos solos do Estado de Santa Catarina. Santa Maria, Universidade Federal de Santa Maria. 494p.

SRÓDON J. 2006. Identification and Quantitative Analysis of Clay Minerals. In: BERGAYA F et al. (Eds.). Handbook of Clay Science. Elsevier Science. p. 765- 787.

STEVENSON FJ. 1982. Humus chemistry: genesis, composition, reactions. New York: John Wiley \& Sons. 443p.

TEDESCO MJ et al. 1995. Análise de solo, plantas e outros materiais. Porto Alegre: UFRGS. 174p. 